\title{
DEVELOPING AN E-BUSINESS SYSTEM TO IMPROVE THE DOWNSTREAM PHARMACEUTICAL SUPPLY CHAIN (A STUDY ON THE EGYPTIAN MARKET)
}

\author{
SANDRA HADDAD \\ College of International Transport and Logistics - Arab Academy for Science, Technology and \\ Maritime Transport,Egypt, Sandra.haddad@aast.edu, sandra.haddad16@gmail.com
}

\begin{abstract}
Pharmaceutical products are considered sensitive products that require a well-managed distribution channel as they impact human lives. The aim of this research is to investigate the applicability of improving the downstream of the pharmaceutical supply chain (distribution channel) in Egypt through developing an Ebusiness system. The study has adopted a deductive approach. Qualitative and quantitative methodologies were followed respectively. Qualitative in-depth interviews were conducted to get a better understanding of the situation in Egypt followed by a structured survey to test and verify the significance and the relation of the extracted variables using statistical tools. This resulted in highlighting significant variables impacting the relationship between pharmaceutical retailers (pharmacies) and consumers and the applicability of introducing an e-business retailing application that improves downstream chain performance by facilitating transactions i.e. easily locating the required medicine, matching consumers and retailers and spotting the inventory level in the distribution channel for better management solutions.
\end{abstract}

Keywords: case study, distribution, downstream supply chain, pharmaceutical products

\section{INTRODUCTION}

Humans everywhere and everyday are attached to common products affecting their health; these are pharmaceutical products. Pharmaceutical products are counted as the most sensitive products, they require an efficient distribution channels, and they can affect people and their health if they are not distributed in an effective way. The changing nature of distribution and the reduced wholesaler models, are beginning to have a significant impact in some countries. In principle, changes in the distribution model should make the process of delivering medicines from factory gates to the patient bed-side more efficient and cost-effective (Kanavos et al., 2011). Yet, there seem to be some concerns about the availability of medicines in the markets. Different stakeholders (manufacturers, wholesalers, retailers) of the supply chain have different perspectives about incentives and disincentives in this process. From patients/consumers side access to medicines is a vital factor (WHO, 2017). Supply chain of this type of products is critical especially in Egypt, according to the shortage of medicines in the market and the economical inflation attacking the country. Thus, this research attempts to find a solution to enhance the downstream pharmaceutical supply chain in Egypt through an electronic system supported by an application to ease locating the required medicine, match consumers and pharmacies possessing the required medicine and spotting the inventory level in the distribution channel for better management solutions.

\section{LITERATURE REVIEW}

The pharmaceutical industry supply chain covers drug research, development, manufacture; distribution and application through a range of healthcare services, together with all the ancillary businesses that help these different stages function effectively. The

https://doi.org/10.24264/icams-2020.III.7 
Developing an E-business System to Improve the Downstream Pharmaceutical Supply Chain (A Study on the Egyptian Market)

pharmaceutical and healthcare industry is extremely complex because it involves so many markets, products, processes and intermediaries. It is also globally heavily regulated and used by everyone in life. Changes in any area impact upon the others and environmental factors such as regulatory change, pricing, or actions by competing bodies, influence the whole supply chain in ways that are not easily understood or effectively managed. Distribution usually gets delegated to third-party logistics and wholesalers in this industry and falls behind when it comes to channel management in comparison to other industries. This means that only a limited amount of information about patients' demand and product flow that is shared with supply chain partners (Xie and Breen, 2012).

\section{Challenges in Pharmaceutical Supply Chain}

The slow growth for the industry had also been a major challenge in the recent past. Innovation rates in the industry have shown considerable decline because of the long time spent in the development of new drugs. Drug prices rise as high as 65 percent than the acceptable international standards in under-developed countries. In addition to the low availability of cheap medicines in the market. Insufficient funding, inability to forecast accurately, lack of incentives for maintaining stocks, inefficient distribution systems and conversion of prescriptions for private resale have encouraged the low accessibility of cheap medicines that are essential for the primary healthcare sector (WHO, 2017). Singh et al. (2016) concentrated on risks and uncertainties related to the recovery of pharmaceutical drugs such as timing, quality, quantity and variety of returns; estimation of operation and cost-related parameters for reverse supply networks; customer behavior and preferences; decisions for product returns; and cost of coordination along the reverse supply chain. Pharmaceutical supply chain is observed as more complex because it demands the active role of different stakeholders such as pharmaceutical manufacturers, wholesalers, distributors, customers, information service providers and regulatory agencies. Given these complexities, the pharmaceutical supply chain lacks sufficient research work. It is also felt that because of lack of research, the pharmaceutical sector in developing countries is unable to contribute significantly in global markets (Bhakoo and Chan, 2011; Singh et al., 2016).

\section{Case of Egypt}

The domestic pharmaceutical industry in Egypt is strong, with a presence of around 120 pharmaceutical companies, of which less than 10 are multinationals with local production branches. There are 17 private sector companies in the industry, together with 9 multinational pharmaceutical players. The pharmaceutical companies operating in Egypt come under three categories: public sector companies, private sector Egyptian companies, and multinational companies. Sales of pharmaceutical products consist of generic drugs, over-the-counter (OTC) medicines, and patented drugs (Ngage Consulting, 2017). Although, Egypt is the largest drug producer and consumer in the Middle East and Africa region in terms of volume, the market is fragmented and distribution is unplanned and scattered i.e. ineffective supply chain management practices. Over three-quarters of the local market are controlled by the private sector. One-third of the pharmaceutical market is controlled by the five largest companies. Low labor costs and a large pool of highly trained pharmacists, engineers, and skilled

https://doi.org/10.24264/icams-2020.III.7 
technicians. Local production of finished pharmaceuticals represents some $90 \%$ of domestic consumption. Demand for pharmaceutical products is much higher than supply, nevertheless, imports are limited to APIs - raw materials, as well as patented and difficult-to-produce pharmaceuticals (BMI, 2018; GAFI, 2019).

\section{Effect of Technology on Pharmaceutical Supply Chain}

Digitization possesses a huge potential to assist pharmaceutical companies the mentioned challenges. Digitization has proved its benefits in many industries as companies are enhancing operations through enabling smart, decentralized production via intelligent factories, integrated IT systems, the Internet of Things, and flexible, highly integrated manufacturing systems. Pharmaceutical industry supply chain operations can be significantly transformed via digitization which can lead to improving processes. The use of technology will lead to improved distribution of system and can serve as an effective marketing instrument as online pharmacies are making medicines and pharmaceutical products directly available to patients which is especially necessary nowadays (Ehrhardt, 2016; Nagy et al., 2018).

\section{METHODOLGY}

In this research multiple methods of data collection instruments are being used to raise the level of the research accuracy and precision. As a matter of fact, combining research methods and using triangulation techniques is encouraged. Amaratunga (2002) explained that Triangulation is about combing several methods (e.g. qualitative and quantitative) in the study of a specific subject.

Thus, this research method combines qualitative and quantitative research methods and analysis. The first data collection phase followed a qualitative approach by conducting semistructured interview with a leading pharmaceutical company manager and a number of semistructured interviews with different pharmacies' owners and patients in Alexandria in order to investigate the market situation and challenges facing the pharmaceutical supply chain in Egypt. After reviewing literature and the results of the qualitative phase a few variables were extracted (independent variables) to measure their effect on the applicability of the electronic ordering and matching application (dependent) by both consumers/patients and pharmacies' owners. Thus, hypotheses were proposed for each variable followed by the second data collection phase using quantitative techniques of collection ana analysis by conducting two structured surveys with pharmacists and patients. Then data was analyzed by running a multiple regression model using the statistical tool SPSS. The following are the developed hypothesis:

\section{Pharmacies' Hypotheses}

$\mathrm{H}_{1}$. There is a significant positive relationship between safety and the applicability of the e-business system.

$\mathrm{H}_{2}$ : There is a significant positive relationship between ease of use of the system and the applicability of the e-business system.

$\mathrm{H}_{3}$ : There is a significant negative relationship between price for running this system and the applicability of the e-business system.

https://doi.org/10.24264/icams-2020.III.7 
Developing an E-business System to Improve the Downstream Pharmaceutical Supply Chain (A Study on the Egyptian Market)

$\mathrm{H}_{4}$ : There is a significant positive relationship between realized profit and the applicability of the e-business system.

\section{Patients' Hypotheses}

$\mathrm{H}_{5}$ : there is a significant positive relationship between safety and the applicability of the e- business system.

$\mathrm{H}_{6}$ : there is a significant positive relationship between frequency of ordering and the applicability of the e- business system.

$\mathrm{H}_{7}$ : there is a significant positive relationship between the realized benefit and the applicability of the e- business system.

$\mathrm{H}_{8}$ : there is a significant negative relationship between price of this service and the applicability of the e- business system.

$\mathrm{H}_{9}$ : there is a significant positive relationship between the availability and the applicability of the e- business system.

The following section will discuss and analyze the results of the qualitative and quantitative phases.

\section{DISCUSSION AND ANALYSIS}

This study aims to test the applicability of the new E- business system that can be used to improve the downstream of the pharmaceutical supply chain in Egypt through developing an E-business system. The study firstly conducts semi-structured interviews to verify literature extracted variables that are assumed to have an effect on the implementation of an e-business solution. It also investigates the current pharmaceutical supply chain condition in the Egyptian market. The second phase follows more structured research techniques. The primary data that was collected from the semi-structured interview and the variables that were extracted from the literature are tested using quantitative technique to validate the outcomes of the qualitative phase and to verify the derived hypotheses.

\section{Qualitative Results and Analysis}

This section discusses the results of the analysis of the semi-structured interview with a leading pharmaceutical products' manufacturer, pharmacist and patients. The results are summarized as follows:

There is a major problem concerning the geographical distribution as products are not equally distributed which effects the availability of products in the pharmacies. Focus of the e-system is Egypt should be on the downstream of the pharmaceutical supply chain specially the retailers and the consumers and to exclude manufacturers. Pharmaceutical demand in Egypt is much higher than supply which makes the system somehow ineffective to manufacturers.

From retailer perspective the e-business system needs to be easy in its usage so anyone can use. Accordingly, the ease of use is supported by the interviews. The interviews also revealed the intention of the pharmacies' owners to use the application as long it will help them maximize profit by increasing the number of orders, thus, their market share. In addition, this phase uncovered the need to integrated a swapping function in the application

https://doi.org/10.24264/icams-2020.III.7 
to enable pharmacies to swap stocks or trade among themselves to overcome uneven geographical distribution i.e. excess in one medicine at a pharmacy and shortage of the same medicine at another pharmacy in another location. This service will reduce their loss and accordingly will maximize their profit. Maximizing profit is the second variable that is verified by the pharmacists as it affects the applicability of this e-system.

From consumers perspective the e-business system can especially help consumers with frequent orders. This application will enable them to save much time which supports another independent variable, namely, frequency of ordering medicine by the customer. Availability of the medicines in one of the pharmacies nearby the customer's location is another important variable stressed by patients. The application shall guide the customers to the pharmacy that has the required medicine which will encourage them to use this application.

\section{Quantitative Results and Analysis}

The variables that were extracted from the literature and supported in the qualitative phase were quantitively tested using the statical tool SPSS to investigate the significance of the relationship between these extracted variables on the applicability of the e-business system by both pharmacies and consumers and to verify the derived hypotheses.

\section{Pharmacies Regression Model Results and Analysis}

This study undertook a linear regression model using the statistical tool SPSS for the following pharmacies model:

$\mathrm{APP}=\alpha+\beta_{1} \mathrm{Saf}+\beta_{2}$ Eas $+\beta_{3}$ Pri $+\beta_{4}$ Prof

where APP: refers to the applicability of the new E-business system measured, Saf: safety, Eas: ease of use, Pri: price, Prof: profit.

After running the linear regression using the previous equation the following results are reached. Table 1 shows the result of regression model and the coefficient of every variable and its level of significance on the dependent variable.

Table 1. betas' Coefficients and p- value of each variable of pharmacies

\begin{tabular}{ccc}
\hline Variables & Beta & Sig \\
\hline Safety & .123 & .194 \\
Ease of use & .227 & $.030^{* *}$ \\
Price & -.024 & .792 \\
Profit & .302 & $.003^{*}$ \\
\hline *significant at 0.01 & & \\
$* *$ significant at 0.05 & & \\
$* * *$ significant at 0.1 & & \\
$\mathrm{APP}=\alpha+0.123 \mathrm{Saf}+0.030$ Eas +0.792 Pri+0.003Prof &
\end{tabular}

Safety: The coefficient of the safety is 0.123 which means that there is a positive relation between the independent variable (safety) and the dependent variable (applicability), however, it was not significant which leads to rejecting hypothesis $\mathrm{H} 1$. 
Developing an E-business System to Improve the Downstream Pharmaceutical Supply Chain (A Study on the Egyptian Market)

Ease of use: The coefficient of the safety is 0.227 which mean that there is a significant positive relation between the independent variable (ease of use) and the dependent variable (applicability), which is similar to the result extracted from the semi-structured interviews and leads to accepting the second hypothesis H2. These results mean that it is very critical for the pharmacies that the new E-business system to be simple and not sophisticated.

Price The coefficient of the price is -0.024 which mean there is a negative insignificant relationship between the Price paid by the pharmacies to run the application and the dependent variable (applicability), which is justifiable as the majority of the pharmacies are already offering delivery services bear extra fees this service and increasing their costs in an attempt to increase their market share. Accordingly, this confirms the negative relationship and justifies its insignificance as pharmacies can accept additional fees for running this Ebusiness system. This leads to rejecting hypothesis $\mathrm{H} 3$.

Profit: The coefficient of the profit is 0.302 which means that there is a significant positive relationship between the independent variable (Profit) and the dependent variable (applicability) these results were the same as what was hypothesized in the hypothesis $\mathrm{H} 4$, similar to the result extracted from the semi structured interviews. This indicates that the target of these pharmacies is to maximize their profit, accordingly the fourth hypothesis $\mathrm{H} 4$ is accepted.

Thus, for the pharmacies' hypotheses H2, H4 are accepted and hypotheses H1, H3 are rejected.

\section{Customers' Regression Model Results and Analysis}

The following part shows the results of the regression model for the customer's questionnaire.

This study undertook a following linear regression model using the statistical tool SPSS for the following customers' model:

APP $=\alpha+\beta_{1}$ Saf $+\beta_{2}$ Freq $+\beta_{3}$ Ben $+\beta_{4}$ Pri $+\beta_{5}$ Avail $+\beta_{6}$ beha

where APP refers to applicability of the new E-business system, Saf: safety, freq: frequency, Ben: ease of use, Pri: price is measured, Avail: Availability, Beha: Behavior.

After running the linear regression using the previous equation the following results are reached. Table 2 demonstrates the results of the regression model and the coefficient of every variable and its level of significance on the dependent variable.

Table 2. betas' Coefficients and p- value of each variable of the customer

\begin{tabular}{ccc}
\hline Variable & Beta & Sig \\
\hline 'Safety & .209 & $.062^{* * *}$ \\
Frequency & .051 & .635 \\
Benefit & .030 & .792 \\
Price & -.046 & .658 \\
Availability & .278 & $.009^{*}$ \\
Behavior & .051 & .632 \\
\hline
\end{tabular}

*significant at 0.01

**significant at 0.05

$* * *$ significant at 0.1

https://doi.org/10.24264/icams-2020.III.7 
$\mathrm{APP}=\alpha+0.209 \mathrm{Saf}+0.51$ Freq $+0.030 \mathrm{Ben}+0.046 \mathrm{Pri}+0.278$ Avail +0.051 beha

Safety: The coefficient of the safety is 0.209 which means there is a significant positive relation between the independent variable (safety) and the dependent variable (applicability) which the same as what was hypothesized in the hypothesis H5.It's significance level indicates that it is important for customers to feel safe while using the E-business system, accordingly the hypothesis $\mathrm{H} 5$ is accepted.

Frequency: The coefficient of Frequency is 0.051 which indicates an insignificant positive relation between the independent variable Frequently of the customers' orders and the dependent variable (applicability) which contrasts the result of the semi structured interview and previous scholarly work. However, the significance might be due to survey sample as more than $85 \%$ of the customers who took the questionnaire are less than 35 years old, which means that they have good health and do not order medicines frequently. Nevertheless, H6 is rejected.

Benefit: The coefficient of the benefit is 0.30 which shows an insignificant positive relationship between the expected benefit from using the e-system and the dependent variable (applicability) which again contradicts with literature and the qualitative results and leads to rejecting H7. This result can be again linked to the age demographics of the surveyed sample as since the customers are young and do not order medicine frequently then they are not expecting extra benefit from using the E-business system to order their medicines.

Price: The coefficient of the price is -0.046 which means that there is an insignificant negative relationship between the Price paid by customers to use this service and the dependent variable (applicability) which leads to rejecting H8. Referring to the demographics of the sample which shows that more than $65 \%$ of the customers enjoy a high household income, it explains why the price variable is not significant from the customer point of view.

Availability: The coefficient of the availability is 0.278 which means there is a significant positive relationship between the independent variable (Availability) and the dependent variable (applicability) which confirms hypothesis H9 as was also supported in the semi-structured interviews. This led to accepting hypothesis $\mathrm{H} 9$.

Behavior: The coefficient of the behavior is 0.051 which means that there is an insignificant positive relation between the (customers' attitude) in buying medicines and the dependent variable (applicability). Although a significant positive relationship was stated in hypothesis $\mathrm{H} 10$ and confirmed by scholarly work, $\mathrm{H} 10$ is rejected which might be due to the reason that the majority of the customers who took the questionnaires were males do not usually perform the shopping act or behavior like females in Egypt.

Accordingly, hypotheses $\mathrm{H} 5$ and $\mathrm{H} 9$ are accepted while hypotheses $\mathrm{H} 6, \mathrm{H} 7, \mathrm{H} 8$, and $\mathrm{H} 10$ are rejected because of their weak significance level.

\section{CONCLUSION}

This study aims to enhance the Egyptian downstream pharmaceutical supply chain through introducing an e-business system that facilitates locating medicines in order to overcome availability and unequal geographical distribution issues. Also, the e-system shall help pharmacies swap their stocks to improve geographical distribution of the medicines. Triangulation of qualitative and quantitative data collection methods and analysis were

https://doi.org/10.24264/icams-2020.III.7 


\section{Developing an E-business System to Improve the Downstream Pharmaceutical Supply Chain (A Study on the Egyptian Market)}

followed to investigate the situation in the Egyptian market and examine the variables that might influence the applicability of the proposed e-business system. The variables extracted from the literature and supported in the semi-structured interviews were Benefits, Safety, Behavior, Price, Frequency, Availability, Ease of use and Profit. The variables used in the pharmacies model were Safety, Ease of use, Price, and Profit. The significant variables from the pharmacies' perspective were Ease of use at 0.05 significance level and Profit at 0.01 significant level. On the other hand, the customer model variables were Safety, Frequency, Benefits, Price, Availability and Behavior. The results show that the significant variables according to customers were Safety at 0.1 significant level and Availability at 0.01 significant level. Thus, according to the qualitative and quantitative analysis, it seems that an e-business system that helps patients locate the required medicine easily without the physical search effort and which is safe and easy to use, can be considered applicable to patients in the Egyptian market. Moreover, the e-business system appears to be beneficial to retailers/ pharmacies who want to increase the market share, reach more customers, thus, maximize profit and also want reduce their losses through being enabled to swap stocks with other pharmacies via an easy to use e-platform.

\section{REFERENCES}

Amaratunga, D., Baldry, D., Sarshar, M. and Newton, R. (2002), "Quantitative and qualitative research in the built environment: application of "mixed" research approach", Work Study, 51(1), 1731, https://doi.org/10.1108/00438020210415488.

Bhakoo, V. and Chan, C. (2011), "Collaborative implementation of e-business processes within the health-care supply chain: the Monash Pharmacy Project”, Supply Chain Management: An International Journal, 16(3), 184-193, https://doi.org/10.1108/13598541111127173.

BMI research (2019), Egypt Pharmaceuticals and Healthcare Report [online], available at: https://nationsemergentes.org/wp-content/uploads/2019/02/egypt-pharmaceutical-survey.pdf, accessed 15 August 2020.

Ehrhardt, M. (2016), "The Digital Game-Changer", Pharma Manufacturing [online], available at: https://www.pharmamanufacturing.com/articles/2016/the-digital-game-changer/

GAFI (2019), "Invest in Egypt", Cairo: General authority for Investment and Free Zones.

Kanavos, P., Schurer, W. and Vogler, S. (2011), "The pharmaceutical distribution chain in the European Union: structure and impact on pharmaceutical prices", European Commission, Brussels, Belgium [online], available at: http://eprints.lse.ac.uk/51051/1/Kanavos_pharmaceutical_distribution_chain_2007.pdf

Nagy, J., Oláh, J., Erdei, E., Máté, D. and Popp, J. (2018), “The Role and Impact of Industry 4.0 and the Internet of Things on the Business Strategy of the Value Chain-The Case of Hungary", Sustainability, 10, 3491, https://doi.org/10.3390/su10103491.

Ngage Consulting (2017), "Egypt's Pharmaceutical Sector Following Bold Economic Reforms: Challenges and Opportunities" [online], available at: https://www.ngage-consulting.com/downloads/Pharmaceutical_ PDF_Final_Version_K_and_A.pdf

Singh, R.K., Kumar, R., Singh, P.K. (2016), "Strategic issues in pharmaceutical supply chains: a review", International Journal of Pharmaceutical and Healthcare, 10(3), 234-157, https://doi.org/10.1108/IJPHM-102015-0050.

WHO (2017), "Global Surveillance and Monitoring System for Substandard and Falsified Medical Products" [online] available at: file:///C:/Users/Sandra/Downloads/9789241513425-eng.pdf, Accessed 20 August 2020, https://doi.org/10.1108/13598541211212195.

Xie, Y. and Breen, L. (2012), "Greening community pharmaceutical supply chain in UK: a cross boundary approach”, Supply Chain Management: An International Journal, 17(1), 4053(14), https://doi.org/10.1108/13598541211212195.

https://doi.org/10.24264/icams-2020.III.7 